\title{
Cytokine-induced differentiation of multipotent adult progenitor cells into functional smooth muscle cells
}

\author{
Jeffrey J. Ross, ${ }^{1}$ Zhigang Hong, ${ }^{2}$ Ben Willenbring, ${ }^{1}$ Lepeng Zeng, ${ }^{1}$ Brett Isenberg, ${ }^{3}$ Eu Han Lee, ${ }^{1}$ \\ Morayma Reyes, ${ }^{1}$ Susan A. Keirstead, ${ }^{1}$ E. Kenneth Weir, ${ }^{2}$ Robert T. Tranquillo, ${ }^{3}$ \\ and Catherine M. Verfaillie ${ }^{1}$
}

${ }^{1}$ Stem Cell Institute, University of Minnesota Medical School, Minneapolis, Minnesota, USA. ${ }^{2}$ Veterans Affairs Medical Center, University of Minnesota, Minneapolis, Minnesota, USA. ${ }^{3}$ Department of Biomedical Engineering, University of Minnesota, Minneapolis, Minnesota, USA.

\begin{abstract}
Smooth muscle formation and function are critical in development and postnatal life. Hence, studies aimed at better understanding SMC differentiation are of great importance. Here, we report that multipotent adult progenitor cells (MAPCs) isolated from rat, murine, porcine, and human bone marrow demonstrate the potential to differentiate into cells with an SMC-like phenotype and function. TGF- $\beta 1$ alone or combined with PDGF-BB in serum-free medium induces a temporally correct expression of transcripts and proteins consistent with smooth muscle development. Furthermore, SMCs derived from MAPCs (MAPC-SMCs) demonstrated functional L-type calcium channels. MAPC-SMCs entrapped in fibrin vascular molds became circumferentially aligned and generated force in response to $\mathrm{KCl}$, the L-type channel opener FPL64176, or the SMC agonists 5-HT and ET-1, and exhibited complete relaxation in response to the Rho-kinase inhibitor Y-27632. Cyclic distention ( $5 \%$ circumferential strain) for 3 weeks increased responses by 2 - to 3 -fold, consistent with what occurred in neonatal SMCs. These results provide evidence that MAPC-SMCs are phenotypically and functionally similar to neonatal SMCs and that the in vitro MAPC-SMC differentiation system may be an ideal model for the study of SMC development. Moreover, MAPC-SMCs may lend themselves to tissue engineering applications.
\end{abstract}

\section{Introduction}

In vivo, SMCs are found in the vascular system, as well as in visceral organs, notably the respiratory, genitourinary, and gastrointestinal systems. VSMCs play an important role in angiogenesis, vessel maintenance, and the regulation of blood pressure. Phenotypically, SMCs differ from cardiac and skeletal muscle cells not only by their expression of specific contractile proteins (1) - including $\alpha$-SMA (ACTA2), calponin-1 (CNN1), SM22 $\alpha$ (TAGLN), and smooth muscle myosin heavy chain (SM-MHC; Myh11) - but also by their plasticity or ability to reenter the cell cycle and exhibit a "synthetic" phenotype, secreting ECM proteins $(1,2)$. The involvement of VSMCs in atherosclerosis and hypertension, leading causes of heart failure, underlies the significant interest in understanding the mechanisms that control differentiation of VSMCs. Phenotypic modulation and ECM remodeling properties of SMCs are also of great interest for tissue engineering applications $(3,4)$, as small artery grafts could be created to have mechanical and contractile function. Therefore, the ability to generate SMCs from stem cells would yield an ideal model for the study of SMC development and differentiations and be useful for other applications including tissue engineering.

Several factors confound the study of SMC differentiation, including the heterogeneic ontogeny of SMCs, as SMCs are derived

Nonstandard abbreviations used: $\mathrm{CD}$, cyclic distension; ET-1, endothelin-1; F-MAPC, Fisher rat MAPC; MAPC, multipotent adult progenitor cell; MAPC-SMCs, SMCs derived from MAPCs; Q-RT-PCR, quantitative RT-PCR; RAOSMC, rat aortic SMC; rMAPC, rat MAPC; RUSMC, rat uterine SMC; SD-MAPC, Sprague-Dawley rat MAPC; SM-MHC, smooth muscle myosin heavy chain; SRF, serum response factor. Conflict of interest: The authors have declared that no conflict of interest exists. Citation for this article: J. Clin. Invest. 116:3139-3149 (2006). doi:10.1172/JCI28184. not only from mesoderm, but also neural crest and the proepicardial organ $(1,2)$. In addition, even for SMCs derived from the same ontogenic cell source, considerable differences in gene expression exist (5), and little is know about developmental and phenotypic differences between visceral and VSMCs, with the exception of a few markers (6). To date, characterization of SMCs often is done by demonstrating the presence of $\alpha$-SMA (7), which is also expressed by myofibroblasts, and endothelial cells under certain conditions, and hence not specific for SMCs. SM22 $\alpha$, calponin-1, and SM$\mathrm{MHC}$ are increasingly SMC restrictive, but transient expression in non-SMCs cannot be ruled out (7). Smoothelin (SMTN), another cytoskeletal protein found in mature SMCs, is absent in myofibroblast cells $(8,9)$, providing a potential marker to distinguish between SMCs and fibroblasts, as is the preferentially VSMCexpressed SmLim/CRP2 (CSRP2) (10) transcript. Transcriptional activation of SMC genes by myocardin (MYOCD) and Gata-6 (GATA6) in addition to the serum response factor (SRF) (11) has added to our understanding of transcriptional control of SMC specification and differentiation. Together these SMC-restricted genes provide a template for phenotypic characterization.

In vivo characterization of SMC development has provided evidence for a role for TGF- $\beta 1$ (TGFB1) and PDGF-BB (PDGFB) in SMC specification. TGF- $\beta 1^{-/-}$mice die at E10.5-E11.5 with vascular defects including decreased endothelial/mesenchymal cell contact (12). Similarly, in PDGF-BB ${ }^{-/-}$mice, SMCs are not recruited around vessels, and pericytes are aberrantly located (13). Beyond cytokines, mechanical forces contribute to SMC development and postnatal maturation, as cyclical strain results in upregulation of contractile proteins within SMCs along with increases in ECM secretion (14). 

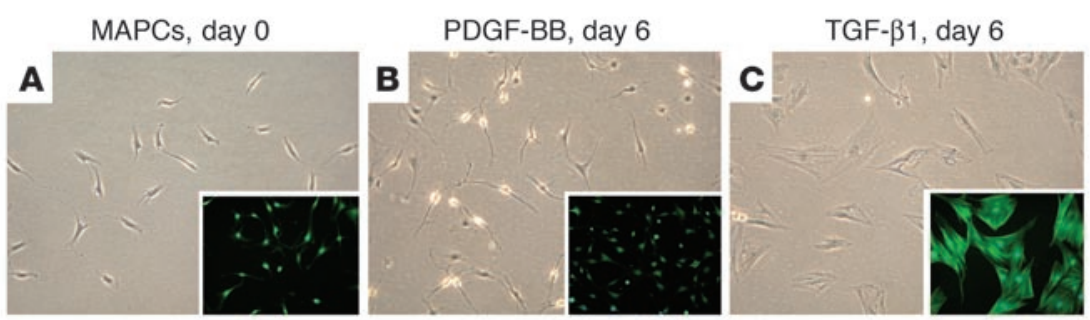

PDGF-BB + TGF- $\beta 1$, day 6
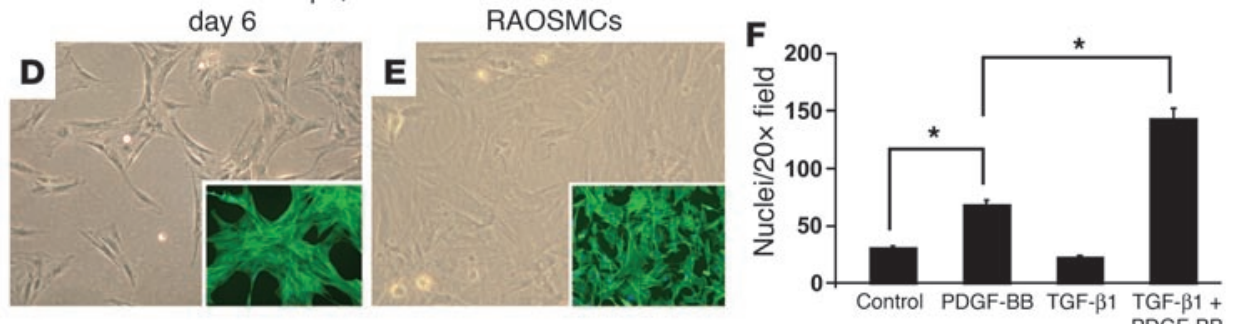

PDGF-BB

\section{Figure 1}

Effects of TGF- $\beta 1$, PDGF-BB, or TGF- $\beta 1$ plus PDGF-BB on SD-MAPC morphology. Phase-contrast images of SD-MAPCs (A); SD-MAPCs treated for 6 days in serum-free medium with $5 \mathrm{ng} / \mathrm{ml}$ PDGF-BB (B), $2.5 \mathrm{ng} / \mathrm{ml} \mathrm{TGF- \beta 1} \mathrm{(C),} \mathrm{or} 5 \mathrm{ng} / \mathrm{ml}$ PDGF-BB and $2.5 \mathrm{ng} / \mathrm{ml}$ TGF- $\beta 1$ (D); or primary RAOSMCs (E). Morphology is representative of more than 10 independent experiments. Magnification, $\times 10$. Phalloidin staining $(\mathbf{A}-\mathbf{E}$, insets; magnification, $\times 10)$ demonstrates that the stress fiber pattern of SD-MAPCs induced with TGF- $\beta 1$ or TGF- $\beta 1$ plus PDGF-BB is similar to that of primary RAOSMCs (E). (F) Cellular density on day 6 of SD-MAPC differentiation $(P<0.01 ; n=4)$.

In vitro SMC differentiation models, including the embryonic carcinoma cell line P19, and several cell line models including Monc-1, PAC1, and 10T1/2 cells (11), have been invaluable in providing insights into the transcriptional control of SMC differentiation over the past decade. More recently, murine ES cells $(15,16)$ and different types of primary adult stem/progenitor cells, including mesenchymal stem cells (MSCs) (17), bone marrow-derived multipotent stem cells (18), neural stem cells (19) and mesoangioblasts (20), have been used to elucidate signals that induce commitment and differentiation of SMCs. Although most of these studies have demonstrated the presence of proteins consistent with SMCs, few have addressed whether the differentiated cells also have functional properties of SMCs.

Here we demonstrate that another adult stem cell population, multipotent adult progenitor cells (MAPCs), can be induced to differentiate in a relatively homogeneous fashion into SMCs, based on gene and protein expression as well as functional characteristics. MAPCs can be cultured without senescence from human, porcine, mouse, and rat marrow, and we have previously published evidence that they can at the single-cell level differentiate into cells of mesoderm (cartilage, bone, adipocytes, skeletal muscle, and endothelium), endoderm (hepatocytes), and ectoderm (neurons and glia) (21-23). MAPCs express the ES cell-specific transcription factor Oct3/4 (POU5F1) (24) but not Nanog. FACS analysis demonstrates $(22,25)$ that MAPCs do not express class I and II MHC, CD34, CD44, CD45. Hence, MAPCs differ from classical MSCs that are Oct4 low/negative but CD44 and MHC class I positive and differentiate essentially into mesodermal cells but not cells of endoderm and ectoderm (26). Compared with mesoangioblasts (27), MAPCs do not express CD34 and Flk1 (KDR), and have a broader differentiation ability. Populations of cells similar proliferation, increasing it by $212 \% \pm 13.4 \%$ or $636 \% \pm 38.5 \%$ compared with PDGF-BB or TGF- $\beta 1$ alone, respectively (Figure 1F).

To substantiate the effect of TGF- $\beta 1$ on SMC differentiation, we used quantitative RT-PCR (Q-RT-PCR) to measure transcript levels of SMC contractile apparatus-specific genes, including $\alpha$-SMA, SM22 $\alpha$, SM-MHC, and calponin-1, along with the transcription factor myocardin (Figure 2, A-E). Transcript levels were compared with those of RAOSMCs. Undifferentiated SD-MAPCs expressed low levels $(\leq 1 \%)$ of SM $22 \alpha$, SM-MHC, myocardin, calponin-1, and $\alpha$-SMA transcripts (Figure 2, A-E). Culture in the presence of PDGF-BB alone $(2.5-100 \mathrm{ng} / \mathrm{ml})$ did not significantly affect expression of these genes, which differs from results of studies using BSSCs. Transcript levels of SM22 $\alpha$, SM-MHC, and calponin-1, $\alpha$-SMA, and myocardin were increased by $361 \pm 9.8-$, $25.1 \pm 1.68-, 373 \pm 136-, 6,830 \pm 430$-, and $93.7 \pm 2.86$-fold, respectively, by day 6 in TGF- $\beta 1$-treated compared with undifferentiated SD-MAPCs. Addition of 5 or 10 rather than $2.5 \mathrm{ng} / \mathrm{ml}$ of TGF- $\beta 1$ did not significantly alter SMC transcript levels (data not shown). Transcript levels increased, but to a lesser extent, when cells were cultured with $5 \mathrm{ng} / \mathrm{ml}$ PDGF-BB combined with TGF- $\beta 1$ (Figure $2, \mathrm{~A}-\mathrm{E})$, consistent with reports indicating that PDGF-BB inhibits the expression of mature SMC markers $(30,31)$.

Expression of contractile proteins was confirmed by immunohistochemical analysis of SD-MAPCs treated with $2.5 \mathrm{ng} /$ $\mathrm{ml}$ TGF- $\beta 1$ for $0,2,4$, and 6 days (Figure $3, \mathrm{~A}-\mathrm{C}$ ). Consistent with the results of the Q-RT-PCR analysis, low levels of SM $22 \alpha$ protein were detected in undifferentiated MAPCs, but $\alpha$-SMA was undetected (Figure 3A). The percentage of organized SM22 $\alpha$ changed dramatically by day 2 as SM $22 \alpha$ localized along stress fibers (Figure $3 A$ ). $\alpha$-SMA was detected in a small fraction of cells on day 4 and more than $50 \%$ of cells by day 6 . Temporally, the expression 


\section{A}

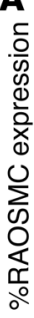

응

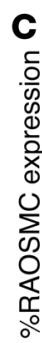

1000

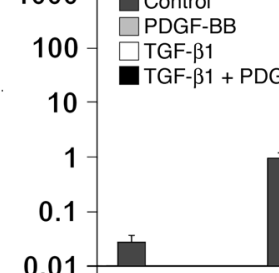

Day 0
$\alpha$-SMA

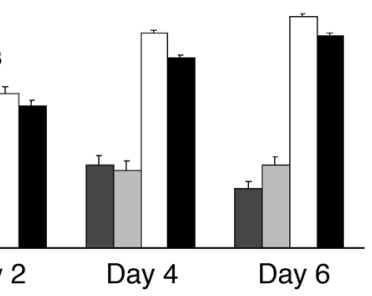

SM-MHC

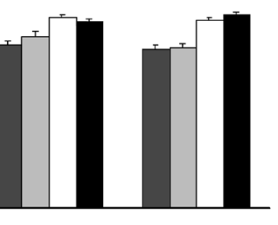

Day 4

Day 6

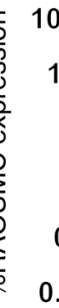

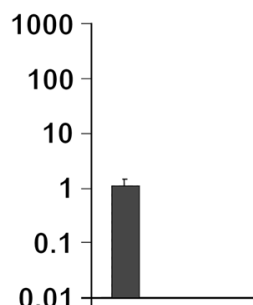

E

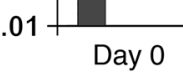

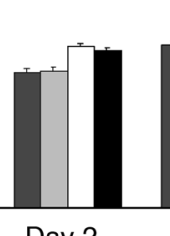

Day 2

Myocardin

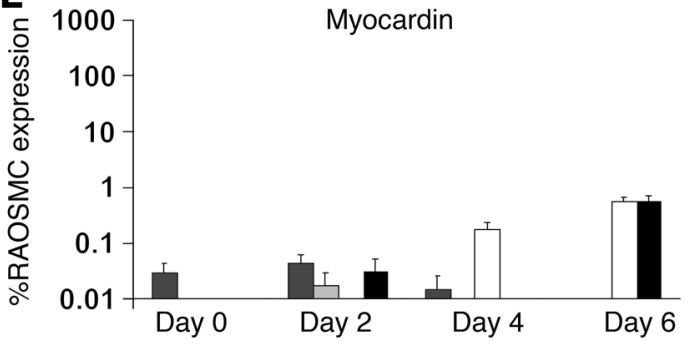

B
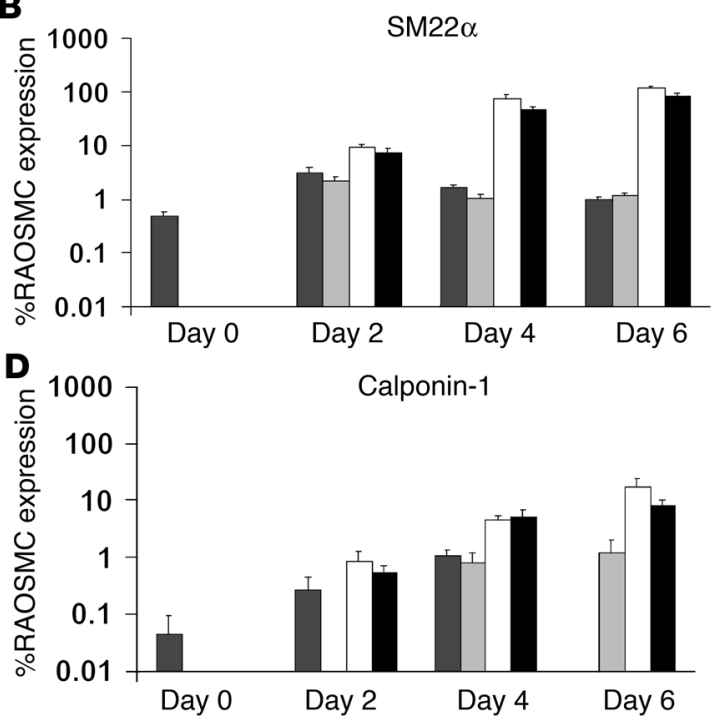

Figure 2

Induction of SMC-specific transcript expression in SD-MAPCs. SD-MAPCs cultured in serum-free conditions with TGF- $\beta 1$, PDGF-BB, TGF- $\beta 1$ plus PDGF-BB, or without cytokine (Control). Expression is reported as percent expression compared with RAOSMCs on days $0,2,4$, and 6 for $\alpha$-SMA (A), SM22 $\alpha$ (B), SM-MHC (C), calponin-1 (D), or myocardin (E). Expression on day 6 of all genes in the presence of TGF- $\beta 1$ was significantly greater than in undifferentiated SD-MAPCs (day 0$)(P<0.01 ; n=3-6)$.

of SM $22 \alpha$ preceded that of $\alpha$-SMA (Figure 3 , A and B), consistent with what has been observed during vascular development in vivo, where SM $22 \alpha$ can be detected in the dorsal aorta at E8.0, 24 hours before the expression of $\alpha$-SMA (32).

We next tested whether SD-MAPC-derived SMCs (SD-MAPCSMCs) could be expanded in culture. When day 6 TGF- $\beta 1$ SDMAPC-SMCs induced with TGF- $\beta 1$ were replated in expansion medium, they proliferated with a doubling time (DT) of approximately 48 hours, significantly slower than undifferentiated MAPCs (DT, $\sim 16$ hours). Passaged SD-MAPC-SMCs maintained expression of SM22 $\alpha, \alpha$-SMA, calponin, and SM-MHC (Figure $3 \mathrm{D})$ as indicated by immunofluorescence, as more than $90 \%$ of cells expressed $\alpha$-SMA protein after 5 passages. Even after 10 population doublings, more than $60 \%$ of cells stained positive for $\alpha$-SMA and calponin (data not shown). When undifferentiated SD-MAPCs or SD-MAPCs treated in the differentiation step with PDGF-BB were plated in expansion conditions (10\% serum), some of the ensuing cells expressed low levels of SM22 $\alpha, \alpha$-SMA, and calponin protein, but they did not express the mature SMC protein SM-MHC (data not shown).

SMC-specific genes, transcription factors, and ECM gene expression were evaluated using a second line of rat MAPCs (rMAPCs), derived from Fisher rats (F-MAPCs). Consistent with data on SDMAPCs (Figure 2), transcripts for $\alpha$-SMA, SM22 $\alpha$, and calponin significantly increased between day 0 and day 6, when F-MAPCs were incubated with $2.5 \mathrm{ng} / \mathrm{ml} \mathrm{TGF- \beta 1} \mathrm{(Figure} \mathrm{4A).} \mathrm{Day} 6$ levels of $\alpha$-SMA, SM22 $\alpha$, calponin, SM-MHC, and smoothelin-B transcripts in F-MAPC-SMCs were $19.1 \% \pm 2.91 \%, 33.0 \% \pm 4.87 \%$, $15.6 \% \pm 1.12 \%, 7.84 \% \pm 0.31$, and $47.6 \% \pm 6.88 \%$, respectively, compared with RAOSMCs (Figure 4A). F-MAPC-SMCs also expressed the transcription factor Gata- 6 at $2.61 \% \pm 0.40 \%$, the preferentially VSMC-expressed protein SmLim/CRP2 at 350\% $\pm 46.7 \%$, collagen type I and III at $88.2 \% \pm 10.8 \%$ and $93.5 \% \pm 9.60 \%$, and the L-type calcium channel $\mathrm{Ca}_{v} 1.2$ at $254.8 \% \pm 16.2 \%$ compared with RAOSMCs (Figure 4, B and C), providing further evidence of an SMC phenotype by day 6 . Following 1 passage in serum containing expansion medium, a further increase in expression of $\alpha$-SMA, SM22 $\alpha$, calponin, smoothelin, myocardin, Gata-6, Smlim/CRP2, and collagen type I and III increased even further, reaching levels similar to those seen in RAOSMCs (Figure 4, A-C) (30). Telokin and $\gamma$-actin (ACTG2), 2 genes reported to be expressed at higher levels in visceral than vascular SMCs $(33,34)$, were expressed at $142.5 \% \pm 21.7 \%$ and $67.9 \% \pm 15.4 \%$ relative to RAOSMCs, respectively, on day 6 of differentiation, while rat uterine SMCs (RUSMCs) expressed telokin and $\gamma$-actin at greater than $90,000 \%$ and greater than $1,300 \%$ relative to RAOSMCs, respectively (Figure 4D). Interestingly, levels of tropoelastin, an important component of VSMCs but not visceral SMCs, were $380 \pm 22$-fold higher in pas- 
A
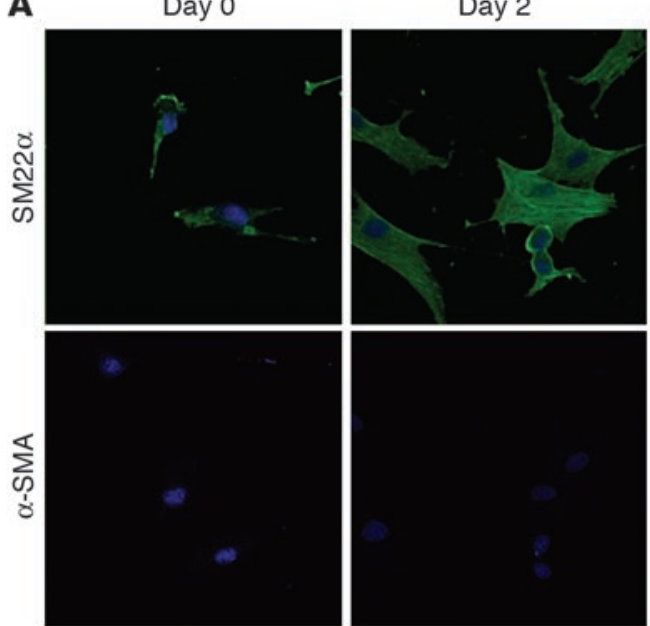

D

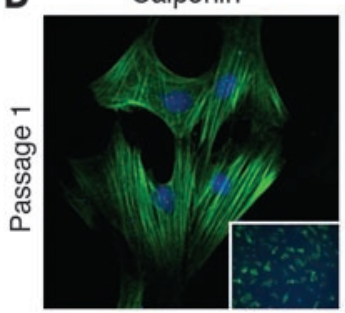

$\alpha-$ SMA

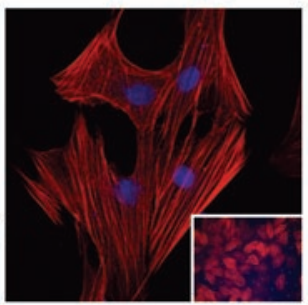

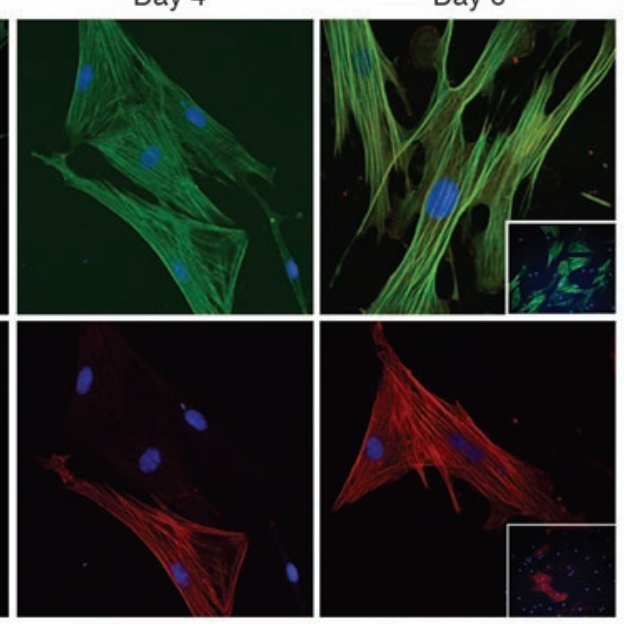

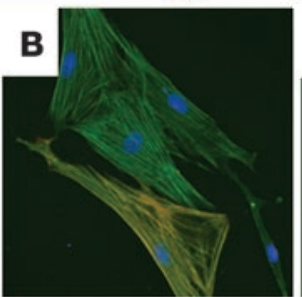

SM-MHC

Day 4

c

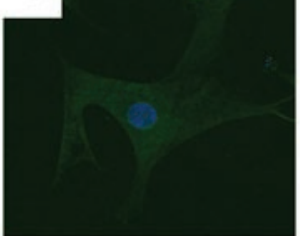

$\mathrm{SM} 22 \alpha$

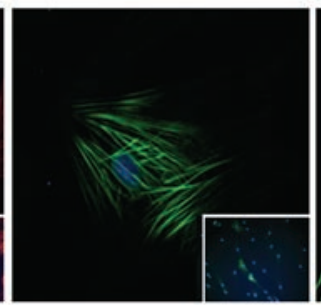

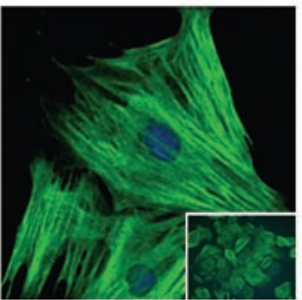

Figure 3

SMC-specific proteins are expressed in SD-MAPCs differentiated with TGF- $\beta 1$. (A) Temporal characterization of SM22 $\alpha$ and $\alpha$-SMA expression on days $0,2,4$, and 6 (magnification, $\times 40)$. SM22 $\alpha$ was detected at low levels on day 0 , which increased and localized to stress fibers as early as day 2. $\alpha$-SMA expression was absent on day 0 and detected by day 4. (B) Colocalization of SM22 $\alpha$ (green) and $\alpha$-SMA (red) further demonstrates that expression of SM22 $\alpha$ precedes that of $\alpha$-SMA. (C) IgG control. (D) Expression of the SMC-specific proteins calponin, $\alpha$-SMA, SM-MHC, and SM22 $\alpha$ in SD-MAPC-SMCs passaged once in expansion medium. Representative example of more than 5 experiments; insets: magnificiation, $\times 10$. sage 1 TGF- $\beta 1$ plus PDGF-BB-induced F-MAPC-SMCs compared with passage 1 TGF- $\beta 1$-induced F-MAPC-SMCs, but were still less than $1 \%$ relative to RAOSMCs.

To further assess the degree of homogeneity of differentiation, we performed FACS analysis for $\alpha$-SMA and SM $22 \alpha$ on undifferentiated F-MAPCs and SD-MAPCs as well as on TGF- $\beta 1$-induced day 6 and passage 1 MAPC-SMCs (Figure 5, A and B). Consistent with immunohistochemical staining and Q-RT-PCR data, the percentage of $\alpha$-SMA- and SM $22 \alpha$-positive cells increased between days 0 and 6 and further increased by passage 1 . Both SD-MAPCs and F-MAPCs yielded relatively homogenous populations of cells that expressed both $\alpha$-SMA and SM22 $\alpha$ at levels similar to those in RAOSMCs.

Finally, we evaluated MAPC-SMCs for expression of other mesodermal markers, including endothelial markers and cardiomyocyte markers. Day 6 TGF- $\beta 1$-induced MAPC-SMCs expressed low levels of Flt 1 and Tie 2 transcripts, but not Flk- 1 or vWF. $\alpha$-Cardiac MHC and troponin $\mathrm{T}$ transcripts were detected at low levels, but not the cardiac-specific transcription factor $\mathrm{Nkx} 2.5$ (data not shown). Expression levels of these markers decreased upon cell passage.

Functional properties of F-MAPC-SMCs. Contraction of SMCs can be elicited by mechanical, electrical, or chemical stimuli. In contractile SMCs, L-type calcium channels $\left(\mathrm{Ca}_{v} 1.2\right)$ are a major route for entry of $\mathrm{Ca}^{2+}$ ions responsible for contraction (35). We used the whole-cell patch clamp technique utilizing the L-type channel agonist FPL64176 and antagonist nifedipine to detect functional L-type calcium channels in undifferentiated and differentiated F-MAPCs compared with RAOSMCs. Undifferentiated F-MAPCs lacked inward current in the presence of FPL64176 (Figure 6, A and B) as did F-MAPCs treated with PDGF-BB (data not shown). In comparison, passage $1 \mathrm{~F}-\mathrm{MAPC}-\mathrm{SMCs}$ differentiated with TGF- $\beta 1$ plus PDGF-BB had voltage-dependent increases of inward current that were enhanced by FPL64176 and quenched by nifedipine, demonstrating L-type channel specificity (Figure 6, A and B). Quantification of inward current was normalized to cell size $(\mathrm{pA} / \mathrm{pF})$, from a membrane potential of $-90 \mathrm{mV}$ by $10-\mathrm{mV}$ steps to $+50 \mathrm{mV}$ for $120 \mathrm{~ms}$. At $0 \mathrm{mV}$, functional L-type $\mathrm{Ca}^{2+}$ channels were detected in day 6 TGF- $\beta 1$ plus PDGF-BBinduced F-MAPC-SMCs $(-3.65 \pm 0.68 \mathrm{pA} / \mathrm{pF})$ compared with TGF- $\beta 1$-induced F-MAPC-SMCs $(-1.51 \pm 0.54 \mathrm{pA} / \mathrm{pF})$ or undifferentiated F-MAPCs $(-0.36 \pm 0.21 \mathrm{pA} / \mathrm{pF})$ (Figure 6C). Following passage, the current density of TGF- $\beta 1$ - and TGF- $\beta 1$ plus PDGF$\mathrm{BB}-$ induced F-MAPC-SMCs increased to $-5.33 \pm 1.23 \mathrm{pA} / \mathrm{pF}$ and $-6.68 \pm 1.30 \mathrm{pA} / \mathrm{pF}$, respectively, similar to that of RAOSMCs $(-6.60 \pm 2.37 \mathrm{pA} / \mathrm{pF})$ at $0 \mathrm{mV}$ (Figure 6C)

We next tested whether day 6 TGF- $\beta 1$-induced F-MAPC-SMCs could remodel fibrin when entrapped, as we have shown for neonatal RAOSMCs $(4,36)$. After 5 weeks, F-MAPC-SMCs entrapped 
A
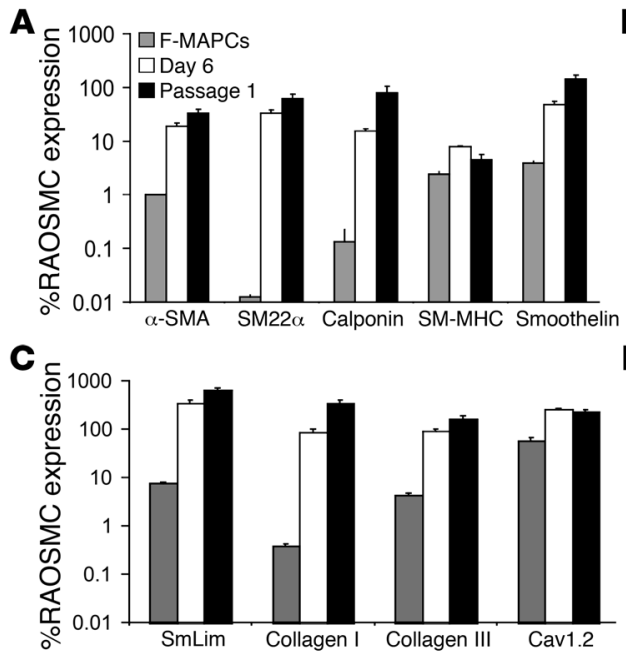

B

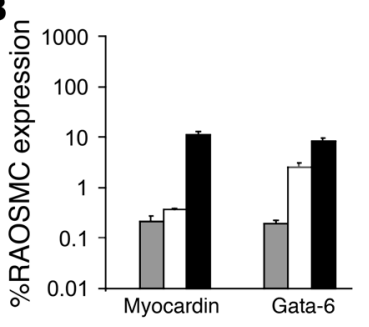

D

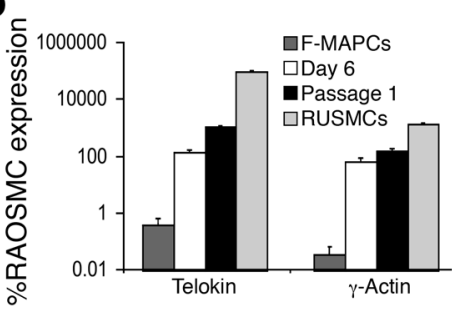

Figure 4

Expression of genes encoding structural proteins, transcription factors, and ECM transcripts in F-MAPCs. (A) Expression levels of $\alpha$-SMA, SM22 $\alpha$, calponin, SM-MHC, and smoothelin, expressed as percentage of RAOSMC expression, significantly increased from day 0 to day $6(P<0.01 ; n=6)$ and further increased to levels similar to those in RAOSMCs by passage $1(P<0.01 ; n=6)$, with the exception of SM-MHC. (B) Low levels of the SMC transcription factors myocardin and Gata- 6 were present at day 0 and increased by day 6 and passage 1. (C) Expression of the preferentially expressed VSMC transcript SmLim/CPP-2 was greater than that observed in RAOSMCs. Collagen type I and III mRNAs were expressed at levels similar to those in RAOSMCs by day 6 and further increased by passage $1(n=6)$. (D) Day 6 and passage 1 expression levels of telokin and $\gamma$-actin mRNA are similar to those in RAOSMCs and significantly lower than in visceral RUSMCs $(P<0.01 ; n=6)$.

in $100 \mu \mathrm{l}$ fibrin (330 $\mu \mathrm{g}$ fibrin) hemispheres and cultured in media-equivalent medium supplemented with $2.5 \mathrm{ng} / \mathrm{ml}$ TGF- $\beta 1$ secreted $91.6 \pm 3.24 \mu \mathrm{g}(n=5)$ collagen, resulting in a remodeled tissue with defined mechanical properties (average ultimate tensile strength [UTS] of $0.15 \pm 0.027$ megapascals [Mpa] [ $n=4$ ] and a tensile tangent modulus of $0.66 \pm 0.06 \mathrm{Mpa}[n=4]$ ), comparable to results of previous studies utilizing adult and neonatal RAOSMCs $(4,36)$. Hemispheres containing F-MAPC-SMCs cultured without TGF- $\beta 1$ secreted only $10.0 \pm 3.5 \mu \mathrm{g}$ collagen $(n=5)$. Furthermore, histological analysis with Masson's trichrome staining demonstrated the continued remodeling effect of TGF- $\beta 1$ on F-MAPC-SMCs, that is, an increase in collagen synthesis and organization of fibrils (Figure 7B) compared with F-MAPC-SMCs entrapped and cultured without TGF- $\beta 1$ (Figure 7A). Using tubular casting molds $(4,37)$, fibrin-entrapped F-MAPC-SMCs cultured with TGF- $\beta 1$ for 9 weeks (Figure 7C) yielded constructs with a defined geometric shape and lumen. Masson's trichrome staining revealed an outer layer of remodeled fibrin, with significant collagen deposition, and an unremodeled inner layer of fibrin with decreased cell density (Figure 7E). Fibrin constructs seeded with endothelial cells failed to compact and remodel the fibrin matrix (Figure 7F).

Results from studies of developmental processes as well as the development of engineered tissues provide evidence that mechanical forces affect the expression of contractile SMC proteins and the properties of ECM $(14,38)$. Previously we reported that long-term cyclic distension (CD) enhanced mechanical properties and induced a contractile phenotype in neonatal RAOSMCs

in collagen-based constructs (39). Utilizing our previously described CD bioreactor, passage 1 F-MAPC-SMCs, neonatal RAOSMCs, or endothelial cells were entrapped in fibrin ring constructs (Figure 6D) and allowed to compact for 2 weeks, and then RAOSMC and F-MAPCSMC constructs were subjected to either CD ( $5 \%$ circumferential strain for 0.25 seconds every 1.75 seconds $[0.5 \mathrm{~Hz}]$ ) or static conditions for an additional 3 weeks. Endothelial constructs failed to remodel and therefore did not demonstrate the required mechanical properties for initiation of $\mathrm{CD}$.

Contractile responses were measured by changes in total force. In the absence of $\mathrm{CD}$, both neonatal RAOSMCs and F-MAPC-SMCs generated force in response to $\mathrm{KCl}$ depolarization, the L-type channel opener FPL64176, and the SMC agonists serotonin (5-HT) and endothelin-1 (ET-1) (Figure 8, D and E). In addition, complete relaxation (vasodilatation) was recorded following the addition of the Rho-kinase inhibitor Y-27632 during a $60-\mathrm{mM} \mathrm{KCl}$-induced contraction (Figure $8 \mathrm{C}$ ), with no effect following the addition of acetylcholine. CD conditioning increased contractility of F-MAPC-SMCs (Figure 7E) in response to $60 \mathrm{mM} \mathrm{KCl}(258 \% \pm 81.4 \%)$ and 5 -HT $(206 \% \pm 34.9 \%)$, with a nonsignificant increase for FPL64176 $(170 \% \pm 43.3 \%)$ and ET-1 $(118 \% \pm 16.8 \%)$ as compared with static cultured constructs. The increased contractility in $\mathrm{CD}$ constructs was similar to what we observed for the response of CD neonatal RAOSMC constructs (Figure $8 \mathrm{D})$ to $\mathrm{KCl}(165 \% \pm 10.0 \%)$, 5 -HT $(161 \% \pm 11.8 \%)$, and FPL64176 (472\% $\pm 57.9 \%)$. The exception was a reduction in response of neonatal RAOSMCs to ET-1 (55.0 \pm 4.84$)$ following CD compared with static cultured constructs. While contractility increased in CD samples, the amount of collagen and elastin production as assayed by hydroxyproline or alkaline extraction, respectively, were similar in static and CD samples (Figure 8, F and G). Expression of $\mathrm{Ca}_{v} 1.2(465 \% \pm 84.3 \% ; n=4)$, collagen type III $(302 \% \pm 56.7 \% ; n=4)$, and elastin $(575 \% \pm 157 \%$; $n=4)$ mRNA was significantly higher in CD constructs $(P<0.01)$ (Figure $8 \mathrm{H}$ ). The expression of SM-MHC mRNA was increased $(256 \% \pm 80.9 \% ; n=4)$, but not significantly; however transcript levels of other SMC genes (smoothelin, $\alpha$-SMA, and calponin) were similar in static and $\mathrm{CD}$ constructs.

$S M C s$ can be generated from MAPCs from multiple species. Finally, we assessed whether MAPCs from other species would respond in a similar fashion to the SMC-inducing cytokines. We tested the effect of TGF- $\beta 1(2.5 \mathrm{ng} / \mathrm{ml})$ and PDGF-BB $(5 \mathrm{ng} / \mathrm{ml})$ on the differentiation of murine, porcine, and human MAPCs (Figure 9, A-C). As is shown in Figure 9, culture of all 3 MAPC populations with TGF- $\beta 1$ and PDGF-BB resulted in significant increases $(P<0.05 ; n=6)$ in SMC transcript levels by day 6 compared with those in undifferentiated MAPCs (day 0). Immunofluorescence for $\alpha$-SMA and calponin of human and swine MAPC-SMCs confirmed the results (Figure 9D). Hence, the differentiation scheme initially developed for rMAPCs also induces an SMC-like phenotype in MAPCs from mice, swine, and humans. 
A
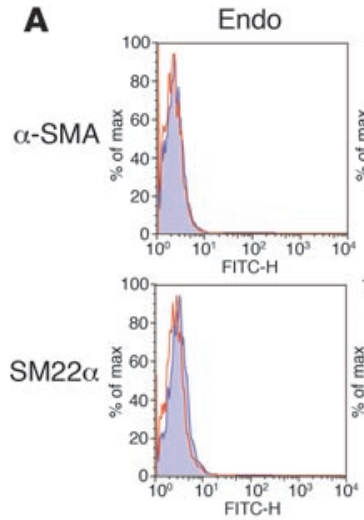

$\lg G$
RAOSMCS
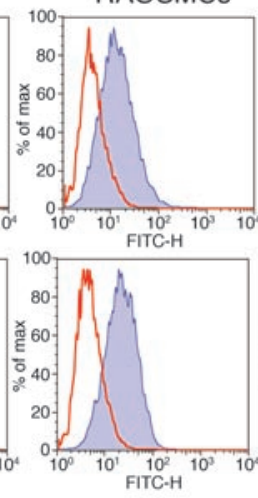

B
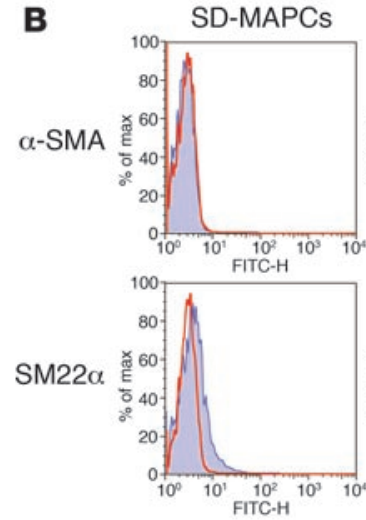

F-MAPCs
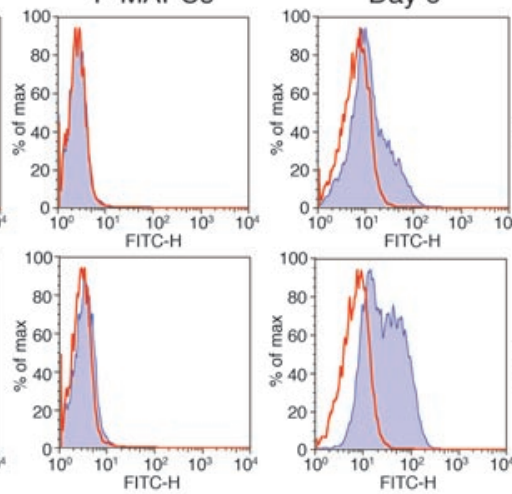

Day 6
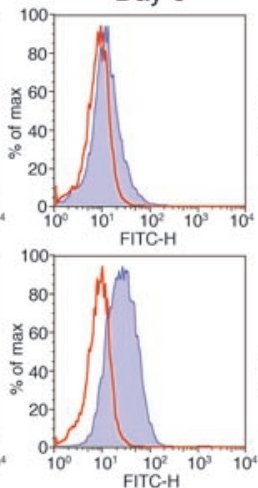

Passage 1
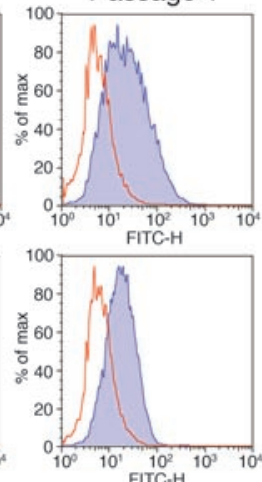

Passage 1
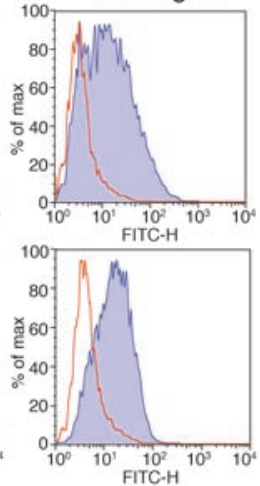

Figure 5

FACS analysis of F-MAPCs and SD-MAPCs for $\alpha$-SMA and SM22 $\alpha$ expression. The expression profiles for $\alpha$-SMA and SM22 $\alpha$ during TGF- $\beta 1$ differentiation of F-MAPCs (A) and SD-MAPCs (B) display similar population shifts at day 6 and passage 1, achieving levels equivalent to those in RAOSMCs at passage $1(n=3)$. Endothelial cells (Endo) failed to express either $\alpha$-SMA or SM22 $\alpha$.

\section{Discussion}

Results from the present studies define what we believe to be a novel system for the derivation of phenotypic and functional SMCs from MAPCs of multiple species by the induction with TGF- $\beta 1$ or TGF- $\beta 1$ plus PDGF-BB in serum-free conditions.

MAPCs differentiate into an SMC phenotype via developmentally appropriate steps. During development $\alpha$-SMA and SM22 $\alpha$ (40) are first detected in mouse embryos at E9.5, followed by the expression of calponin-1, smoothelin, and SM-MHC (41). Here we demonstrate that incubation of MAPCs with TGF- $\beta 1$ in serum-free conditions induces SM $22 \alpha$ and $\alpha$-SMA transcripts and protein by day 2 and day 4, respectively, consistent with kinetics reported by Zhang et al. using SM22 $\alpha$ LacZ knock-in ES cells (32). We detected calponin-1, smoothelin, and SM-MHC as early as day 4 of differentiation, levels of all of which increased further when MAPC-SMCs were passaged. Likewise, transcript levels for the SMC transcription factors myocardin and Gata- 6 increased progressively from day 0 to passage 1 .

Transient expression of many SMC genes has been reported in endothelial, cardiac muscle, and myofibroblast cells (1). Although some endothelial transcripts and cardiac muscle transcripts could be detected early during differentiation, they could no longer be detected once MAPC-SMCs were passaged, strongly suggesting that expression of SMC transcripts and proteins represent differentiation of MAPCs to SMCs. Furthermore, we detected high levels of smoothelin-B, reported to be absent in myofibroblasts
(8); Smlim/CRP2 (10), a cofactor between Gata-6 and SRF (42) expressed preferentially in VSMCs; and the relative SMC-specific L-type channel $\mathrm{Ca}_{v} 1.2$ (35) during differentiation. We also demonstrated that transcript levels of telokin and $\gamma$-actin, genes reported to be more highly expressed in visceral than VSMCs $(33,34)$, in day 6 MAPC-SMCs were similar to those detected in RAOSMCs but significantly lower than levels detected in RUSMCs (Figure 4D), suggestive of a vascular specificity.

The notion that TGF- $\beta 1$ is one of the key cytokines required for SMC differentiation is well established (12), and there is considerable evidence that TGF- $\beta 1$ may play a dual role in SMC differentiation, being important for both initial commitment and further differentiation to SMCs (16). Our finding that initial expression of SMC markers, as well as further differentiation in $2 \mathrm{D}$ and $3 \mathrm{D}$ culture systems to a more mature SMC phenotype, requires TGF- $\beta 1$ is consistent with this notion.

The role of PDGF-BB in SMC differentiation is more controversial. During development, PDGF-BB is involved in the recruitment of pericyctes and SMC precursors to endothelial cells (43). Postnatally, PDGF-BB is highly expressed in vivo in areas of proliferating SMCs, such as in response to vascular injury and atherosclerosis; and there is evidence that blocking PDGF-BB or its receptor inhibits neointimal thickening (7). Thus, PDGF-BB appears to be responsible for phenotypic modulation and dedifferentiation of SMCs in vivo. There is also evidence that PDGF-BB suppresses expression of markers consistent with terminal differentiation in 
A

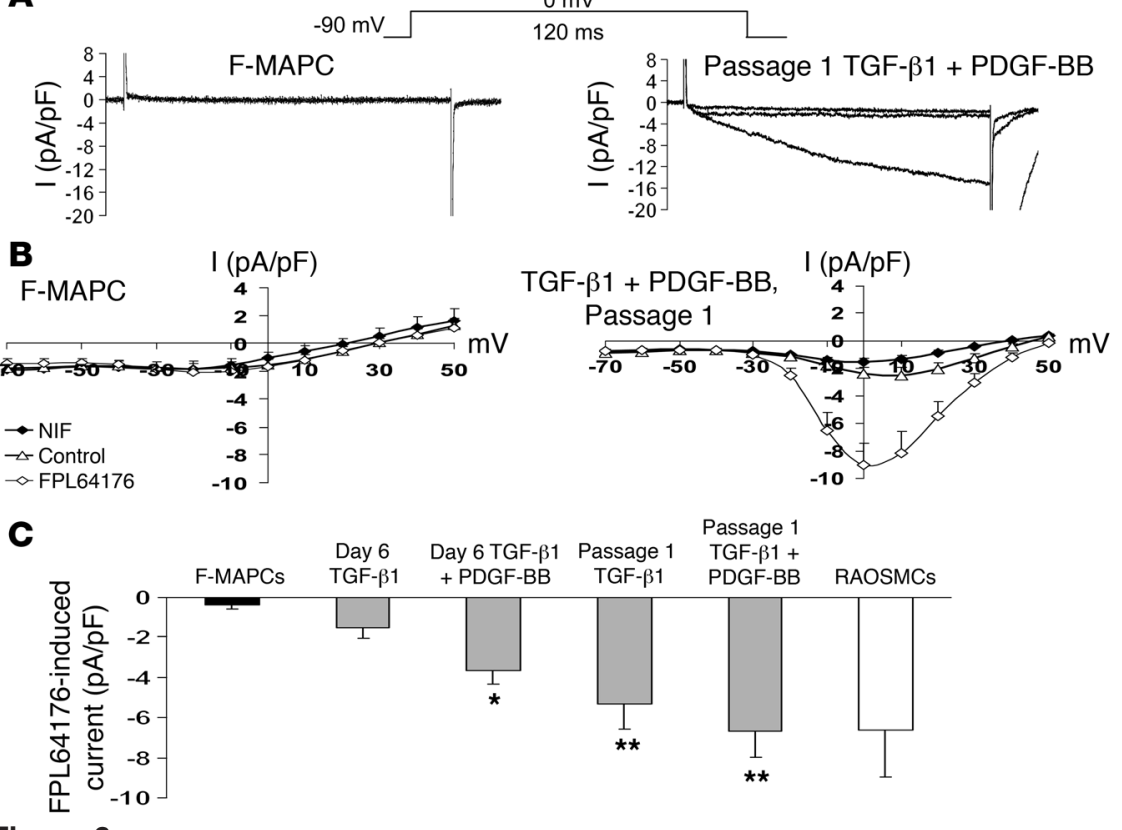

Figure 6

Characterization of L-type $\mathrm{Ca}^{2+}$ channels by whole-cell patch clamp in F-MAPC-SMCs. (A) A representative current recording trace of a day 0 F-MAPC or a passage 1 F-MAPC-SMC differentiated with TGF- $\beta 1$ plus PDGF-BB. The inward calcium current induced by $300 \mathrm{nM}$ FPL64176 (L-type calcium channel opener) in passage 1 F-MAPC-SMCs was completely inhibited by $3 \mu \mathrm{M}$ nifedipine (right), while current was not induced to a significant extent by 300 nM FPL64176 (left). (B) Corresponding I-V plot for F-MAPC and passage 1 F-MAPC-SMC differentiated with TGF- $\beta 1$ plus PDGF-BB. Current is given in $\mathrm{pA} / \mathrm{pF}$ and membrane potential in $\mathrm{mV}$. Cells were voltage clamped at a holding potential of $-90 \mathrm{mV}$, and currents were evoked by $+10-m V$ steps to $+50 \mathrm{mV}$ using test pulses of 120 -ms duration. (C) Quantification of inward current in the presence of FPL64176 while the membrane potential was held at $0 \mathrm{mV}$ for each cell group demonstrates the development of significant inward current in day 6 TGF- $\beta 1$ plus PDGF-BB-differentiated F-MAPC-SMCs and inward current similar to that in RAOSMCs by passage 1 in both TGF- $\beta 1-$ and TGF- $\beta 1$ plus PDGF-BB-differentiated F-MAPC-SMCs $\left({ }^{\star} P<0.05,{ }^{\star \star} P<0.01\right.$ compared with F-MAPCs; $\left.n=8-10\right)$.

vitro, including SM22 $\alpha$ and SM-MHC (44), and induces a proliferative and synthetic SMC phenotype (7). Of note, the effect of PDGF-BB in vitro appears to be culture condition dependent, and inhibition of mature SMC marker expression is only observed in low-density cultures but not when cells are growth-arrested by culture at subconfluent density in serum-free conditions or when maintained at high cell density in serum-replete conditions (44). Whereas PDGF-BB added to the initial differentiation culture, wherein MAPCs were plated at low density, decreased expression of $\alpha$-SMA and SM $22 \alpha$ - consistent with the notion that PDGF-BB may inhibit SMC differentiation - the addition of PDGF-BB to the initial 6-day differentiation step significantly increased levels of tropoelastin mRNA, an important ECM component in VSMC development; and PDGF-BB was required for the development of functional L-type calcium channels by day 6 (Figure 6C). Despite the presence of PDGF-BB in subsequent passaging steps wherein cells were passaged once confluent, levels of all SMC-specific markers increased, consistent with the notion that the influence of PDGF-BB on the phenotype of SMC depends on cell density and possibly other culture conditions, such as the presence or absence of serum, which induces SRF, known to be important for SMC differentiation and maturation.
MAPC-SMCs have functional attributes of SMCs. Demonstration of differentiation from stem cells should involve not only detection of structural proteins and/or transcription factors consistent with a differentiated cell type, but also demonstration of functional properties of the differentiated cell type. SMCs express many ion channels and membrane receptors critical for their contractile behavior that are mediated through the $\mathrm{Ca}^{2+} /$ calmodulin-dependent phosphorylation of myosin light chain. Influx of $\mathrm{Ca}^{2+}$ from voltage-activated $\mathrm{Ca}^{2+}$ channels and intracellular stores is the major source of $\mathrm{Ca}^{2+}(35)$. In both visceral and VSMCs, the most important $\mathrm{Ca}^{2+}$-activated channels are the $\mathrm{L}$-type $\mathrm{Ca}^{2+}$ channels, more specifically the relatively SMC-specific isoform, $\mathrm{Ca}_{v} 1.2$ (35). Using whole-cell patch clamp in the presence and absence of the L-type calcium channel agonist FPL64176 and the antagonist nifedipine, we demonstrated that functional L-type channels are present on MAPC-SMCs but not on undifferentiated MAPCs or MAPCs treated with PDGF-BB alone. Functional L-type channels could be detected following the initial induction with TGF- $\beta 1$ plus PDGF-BB on day 6 , and also on passage 1 TGF- $\beta 1$ - or TGF- $\beta 1$ plus PDGF-BB-induced MAPCSMCs, at current densities similar to those in RAOSMCs. These results are consistent with further maturation of MAPC-SMCs after passage 1 and suggest that addition of PDGF-BB to the initial induction phase may accelerate the establishment of functional SMCs.

Functionality and tissue engineering. If one were to consider SMCs generated from stem cells for the creation of bioartificial vessels, using for instance fibrin gel molds, several functional properties of SMCs would need to exist. These include fibrinolysis, collagenesis, and elastogenesis to transform fibrin into SMC-derived ECM with requisite mechanical properties and a physiological (contractile) phenotype, as revealed by contraction and relaxation in response to agonists and relaxants.

Although cells with SMC phenotype have been generated from a multitude of precursor populations (11, 15-20), until recently the function of the presumed SMCs was not evaluated. In 2006, Rodriguez et al. (45) reported that cells expressing SMC-like markers that contract collagen gels can be generated from lipoaspirate stem cells. However, the degree to which SMC transcript levels increased following SMC induction was significantly less (between 1.1- and 1.7-fold) when studies were done using clonally derived populations compared with early-passage bulk cultures. It is unclear whether the functional SMC features observed when bulk cultures were used were compromised by the presence of contaminating SMCs in the lipoaspirate. A second article, by Sinha et al. (46), demonstrated that, utilizing SMC promoter drug selection, a purified population of SMCs can be derived from murine ES cells that respond to SMC agonists such as ET-1 and Y-27632. 

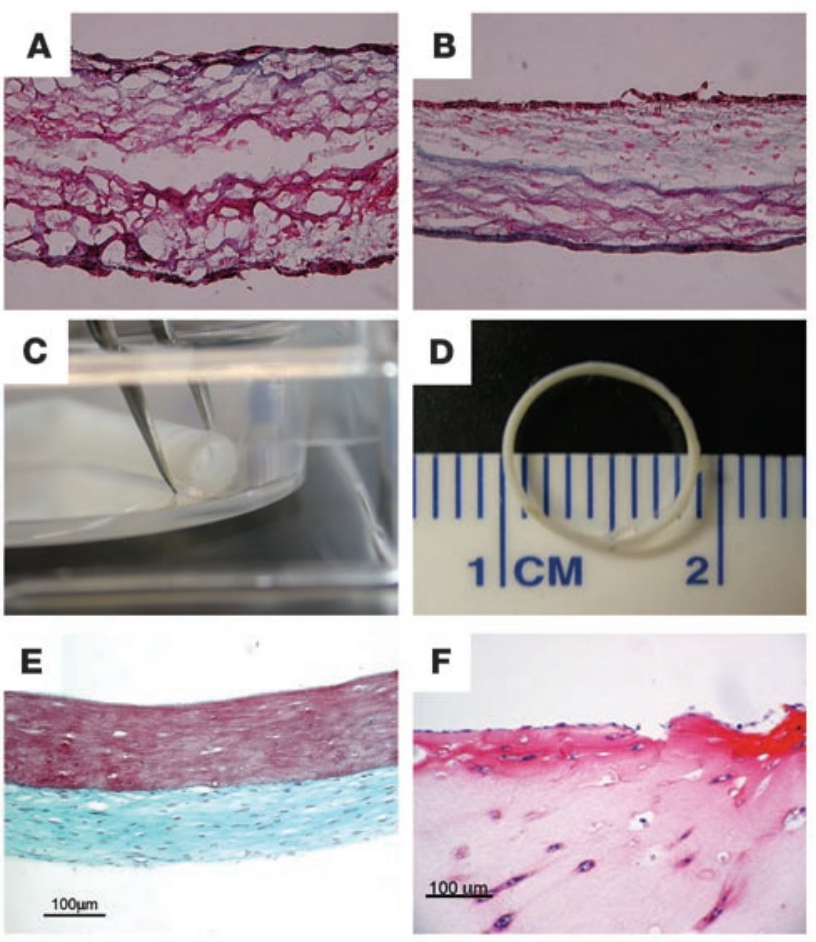

To determine whether MAPC-SMCs exhibit functional properties, we performed a series of studies. First, we tested their ability to remodel fibrin gel and deposit collagen fibrils yielding measurable mechanical properties. We demonstrate that culture in either hemispheres or ring constructs leads to a significant replacement of fibrin by collagen, resulting in constructs with tensile strength and stiffness approximately $50 \%$ of those previously reported in neonatal SMC-fibrin gel constructs (4). Of note, in ring and tubular constructs, the inner luminal areas displayed unremodeled fibrin, which may have occurred because of inadequate nutrient diffusion or because too few cells were loaded in the constructs.

We and others have previously shown that cyclic stretching further enhances SMC differentiation, with improved contractile features $(14,39)$. We demonstrate that cyclically distended ring constructs prepared from F-MAPC-SMCs generated increased isometric contraction force in response to $60 \mathrm{mM} \mathrm{KCl}, 5-\mathrm{HT}$, and the L-type channel agonist FPL64176, similar to those from neonatal SMC constructs, demonstrating that the constructs not only have functional L-type $\mathrm{Ca}^{2+}$ channels but also respond appropriately to 5 -HT and ET-1. The cyclically distended ring constructs also displayed the ability to relax via molecularly appropriate pathways, as the Rho-kinase inhibitor Y-27632 could induce relaxation when added to constructs induced to contract with $60 \mathrm{mM} \mathrm{KCl}$, consistent with the vasodilation that occurs in vivo. Similar results were seen when cyclically distended ring constructs prepared from neonatal RAOSMCs were exposed to these agonists. Thus, MAPCSMCs appear very similar to ES-SMCs (46) not only in transcriptional expression but also responsiveness to ET-1 and Y-27632.

Thus, the observations made using ring constructs further substantiate the notion that MAPCs can differentiate into functional SMCs and suggest that it may be possible to use MAPCs as a source of stem cells for bioengineered small blood vessels. Arterial vessel engineering will require varying degrees of elastogenesis to

\section{Figure 7}

Remodeling properties of F-MAPC-SMCs in fibrin matrix. Collagen synthesis detected by Masson's trichrome staining (green) is apparent in 5-week hemispheres containing F-MAPC-SMCs cultured with $10 \%$ serum $(\mathbf{A})$ or $10 \%$ serum plus TGF- $\beta 1$ (B), as in previous reports for neonatal RAOSMCs. (C) Tubular constructs greater than $2 \mathrm{~cm}$ in length and open lumens were formed when cells were incorporated in fibrin gel surrounding a mandrel for 9 weeks. (D) Vascular rings can be created by week 3. (E) Masson's trichrome staining of 9-week-old F-MAPC-SMC vascular tubes demonstrates that collagen is localized to the outer surface, with the inner luminal surface containing fibrin. (F) Endothelial cells failed to compact and remodel the fibrin matrix.

allow for proper recoil and compliance. Here we demonstrated an increase in tropoelastin transcripts with the addition of PDGF-BB during differentiation or by CD. However, we could not detect deposition of elastin by histological staining. Further modification in differentiation conditions, such as inclusion of bone morphogenetic proteins (BMPs), Wnts, and FGFs and/or mechanical conditioning, may further increase elastogenesis. As arterial elastin is normally localized to the internal elastic lamina separating SMCs and endothelial cells, SMC cocultures may also be exploited to increase localized elastin production. Interestingly, endothelial cells were localized to the luminal surface of the fibrin construct (Figure 7F) and could possibly be used in coculture.

It should be noted that the phenotype of SMCs, as determined by Q-RT-PCR and immunohistochemistry, remained stable for up to 10 passages. However, we did not test whether MAPC-SMCs passaged for 10 population doublings would still exhibit similar functional properties in ring constructs, as did the early-passage cells used here.

Conclusion. In conclusion, we have demonstrated that in response to TGF- $\beta 1$ or TGF- $\beta 1$ plus PDGF-BB, MAPCs express in a temporally appropriate fashion $\mathrm{SMC}$-specific transcripts and proteins and that such MAPC-derived SMCs display functional attributes similar to primary SMC populations, making them a good candidate stem cell population for developmental studies and tissue engineering. The lack of known visceral versus VSMC-specific markers beyond $\gamma$-actin and telokin prevents us at this point from fully elucidating the nature of MAPC-SMCs. The robust differentiation from MAPCs to nearly homogeneous populations of SMCs described here will allow us to further characterize the molecular processes underlying SMC differentiation and visceral versus VSMC fates using, for instance, gene array analysis.

\section{Methods}

MAPC isolation and characterization. MAPCs were isolated from bone marrow of C57BL/ 6 mice, Fisher or Sprague-Dawley rats, humans $(21,22)$, or pigs (47) as described previously. The experiments were approved by the Institutional Animal Care and Use Committee of the University of Minnesota. The detailed protocol for isolation and characterization (25) is described in the Supplemental Methods (supplemental material available online with this article; doi:10.1172/JCI28184DS1).

Smooth muscle differentiation and expansion cultures. MAPCs (rat and human: $2 \times 10^{3}$ cells $/ \mathrm{cm}^{2}$; swine: $3 \times 10^{3}$ cells $/ \mathrm{cm}^{2}$; mouse: $7 \times 10^{3}$ cells $/ \mathrm{cm}^{2}$ ) were plated on $100 \mathrm{ng} / \mathrm{ml}$ fibronectin-coated (Sigma-Aldrich) wells. Differentiation was induced in serum-free MAPC medium $(21-23,48,49)$ supplemented with $2.5 \mathrm{ng} / \mathrm{ml}$ TGF- $\beta 1$ (R\&D Systems) and 0-100 ng/ml PDGF-BB (R\&D Systems), with medium exchanges every 2 days. Following day 6 , expansion medium (high-glucose DMEM [Invitrogen], Penstrep [Invitrogen], 10\% FCS, 


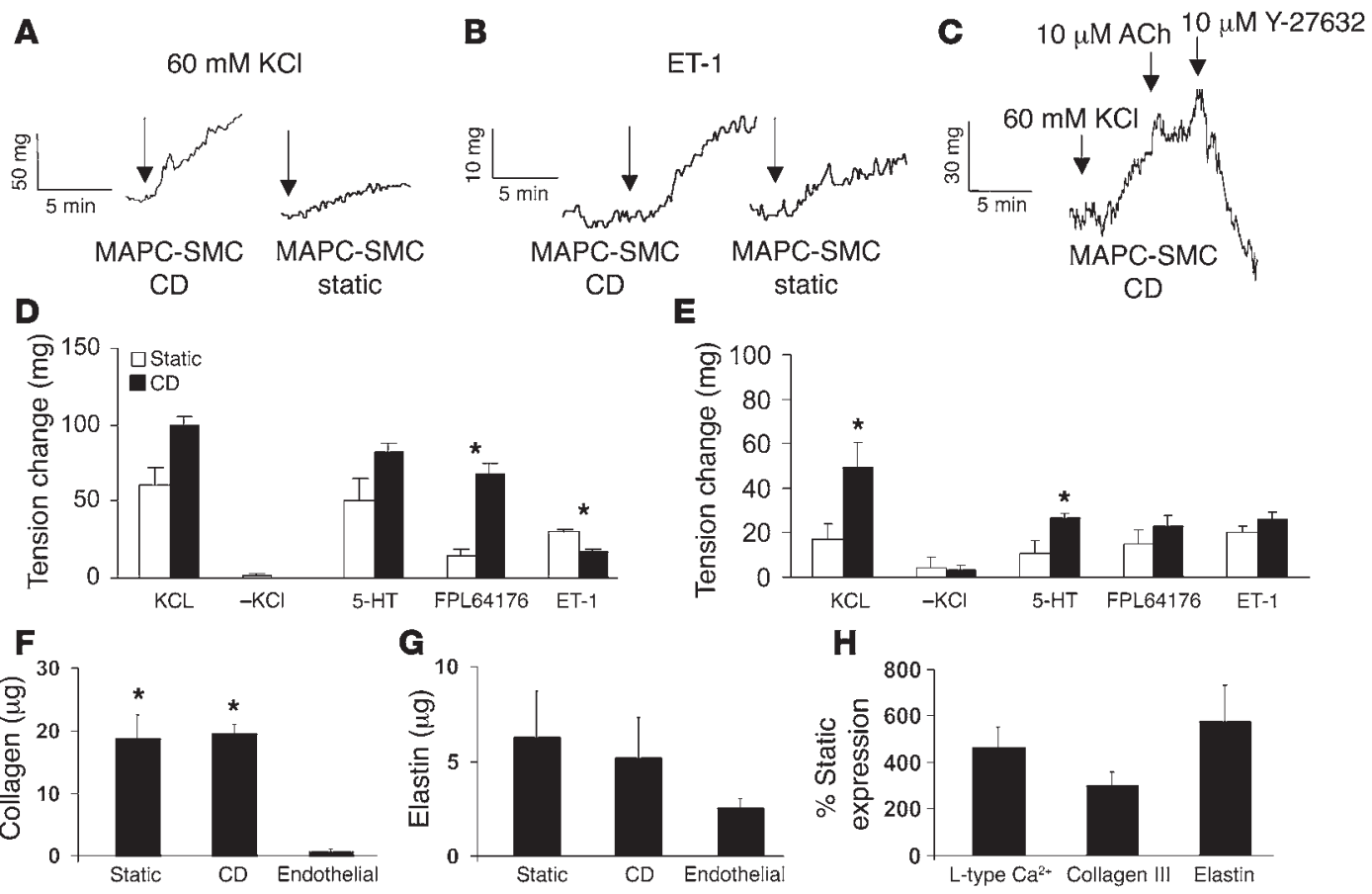

Figure 8

Functional assessment of CD (5\% circumferential strain) on week 5 fibrin ring constructs of F-MAPC-SMCs or rat neonatal SMCs. Contractile responses reported as milligrams in samples exposed to $\mathrm{CD}$ or no strain (static). Traces of induction by $\mathrm{KCl}(\mathbf{A})$ or $\mathrm{ET}-1$ (B) produced greater force in CD-exposed F-MAPC-SMCs compared with static samples. (C) Vasodilation during $\mathrm{KCl}$ contraction was achieved by the Rho-kinase inhibitor Y-27632. Acetylcholine (ACh) had no effect. Five percent strain increased the level of contractility of primary cultured neoRAOSMCs (D) and F-MAPC-SMCs (E) to KCL, 5-HT, and FPL64176, while responses to ET1 were decreased in RAOSMCs following CD $\left({ }^{*} P<0.05 ; n=3-6\right)$. Remodeling levels as determined by total collagen $(\mathbf{F})$ or elastin $(\mathbf{G})$ production were unaffected by CD in F-MAPC-SMC constructs, whereas constructs in which endothelial cells were incorporated did not contain any detectable elastin or collagen $(P<0.01 ; n=4-5)$. (H) Expression of $\mathrm{Ca}_{\mathrm{v}} 1.2$, collagen type III, and tropoelastin was increased in CD compared with static samples after 5 weeks $(n=4-5)$.

$2.5 \mathrm{ng} / \mathrm{ml} \mathrm{TGF-} \beta 1$, and $5 \mathrm{ng} / \mathrm{ml}$ PDGF-BB) was added. Cells were trypsinized and replated every fifth day at $7 \times 10^{3}$ to $10 \times 10^{3}$ cells $/ \mathrm{cm}^{2}$.

Primary cell cultures. Adult RAOSMCs (Cell Applications Inc.) and adult endothelial cells (Cell Applications Inc.) were cultured according to the manufacturer's instructions and used between passages 2 and 5. Adult RUSMCs and neonatal SMCs were isolated by outgrowth in SMC expansion medium and passaged similarly to MAPC-SMCs, as previously described (4).

$R N A$ isolation and Q-RT-PCR reaction. RNA was isolated using an RNeasy kit (QIAGEN) with on-column DNase treatment according to the manufacturer's instructions. cDNA was transcribed with random primers using Invitrogen Superscript with $0.5 \mu \mathrm{g}$ of total RNA per reaction. Q-RT-PCR was performed in an ABI PRISM 7000 system (Applied Biosystems) using SYBR green (Applied Biosystems). Primer sets were designed for each target (Supplemental Table 1) with optimal product lengths of less than 150 bp. Quantification was based on the relative expression suggested by the manufacturer, with GAPDH (Applied Biosystems) normalization of target genes versus: RAOSMC RNA (Cell Applications Inc.) passage 2; mouse total SMC RNA (BD Bioscience); human aortic SMC RNA (Cell Applications Inc.); or porcine aortic SMC RNA (Cell Applications Inc.).

Histology and immunofluorescence. Immunofluorescence was performed on methanol-fixed cells using Cy3-conjugated mouse monoclonal anti- $\alpha$-SMA (C6198; Sigma-Aldrich), mouse monoclonal anti-calponin (C2687; SigmaAldrich), goat polyclonal anti-SM22 $\alpha$ (ab10135; Abcam), or mouse monoclonal anti-SM-MHC (M7786; Sigma-Aldrich). Alexa 488-labeled goat anti-mouse secondary antibody (Invitrogen) was used to detect anti-cal- ponin and anti-SM-MHC antibody localization. Alexa 488-labeled rabbit anti-goat secondary antibody (Invitrogen) was used to detect anti-SM22 $\alpha$ antibody localization. Fibrin constructs were fixed overnight in zinc fixative (BD Biosciences) and paraffin embedded, and $10-\mu \mathrm{m}$ sections were stained with Masson's trichrome stain (Sigma-Aldrich) substituted with Fast Green (Sigma-Aldrich), to enhance the contrast between cells and collagen.

Flow cytometry. Cells were trypsinized, fixed for 10 minutes in cold $2 \%$ paraformaldehyde, washed in PBS, pelleted by centrifugation at $575 \mathrm{~g}$, and resuspended in permeabilization buffer containing $0.1 \%$ (wt/vol) Saponin (Sigma-Aldrich) and $0.05 \% \mathrm{NaN}_{3}$ (Sigma-Aldrich) in PBS for 10 minutes. Cells were blocked in permeabilization buffer containing $0.4 \%$ fish skin gelatin (Sigma-Aldrich) for 30 minutes. Cells were pelleted and divided into 100,000-cell aliquots in permeabilization plus blocking buffer per FACS tube. Cells were incubated for 1 hour with either FITC-conjugated anti$\alpha$-SMA mouse monoclonal (F3777; Sigma-Aldrich), FITC-conjugated mouse $\mathrm{IgG}_{2 \mathrm{a}}$ control (BD Biosciences - Pharmingen), anti-SM22 $\alpha$ goat polyclonal (ab10135; Abcam), or goat IgG control (Jackson ImmunoResearch Laboratories Inc.) antibody. Cells stained for SM22 $\alpha$ were washed twice and incubated for 30 minutes with Alexa Fluor 488-conjugated antigoat secondary antibody (Invitrogen). Cells were analyzed using a FACSCalibur cytometer (BD). Ten thousand events were collected from each experimental group and analyzed against the IgG controls.

Fibrin constructs and mechanical testing. Fibrin constructs were prepared and mechanically tested as previously described (4). Briefly, $5 \mathrm{mg} / \mathrm{ml}$ bovine fibrinogen (Sigma-Aldrich), $25 \mathrm{U} / \mathrm{ml}$ thrombin (Sigma-Aldrich), and a cell 

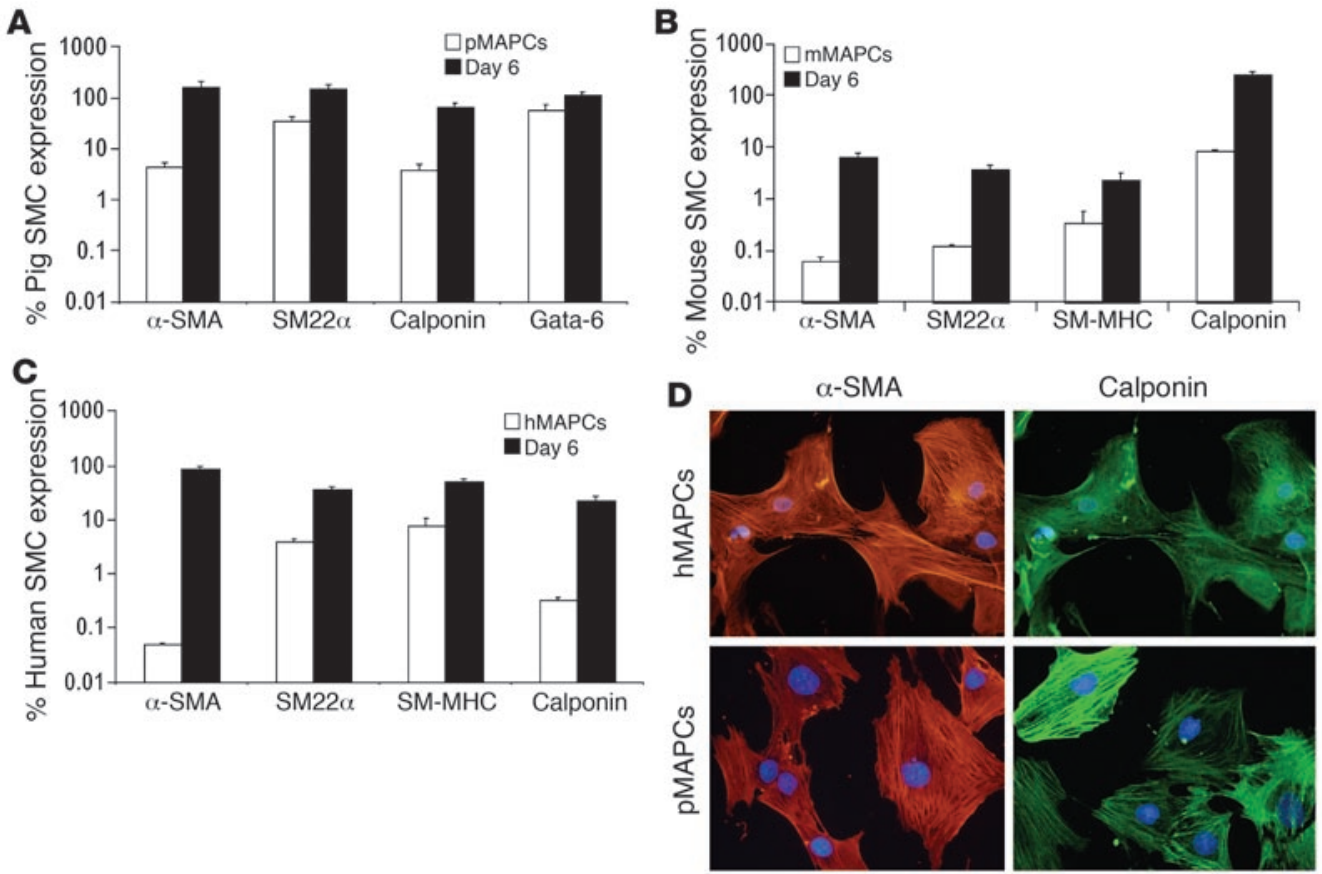

\section{Figure 9}

TGF- $\beta 1$ plus PDGF-BB-induced MAPC-SMC differentiation in mouse, porcine, and human MAPCs. Q-RT-PCR characterization revealed significant upregulation of SMC gene expression by day 6 compared with day $0(P<0.01 ; n=3-6)$ in porcine (A), mouse (B), and human (C) MAPCs (pMAPCs, mMPACs, and hMAPCs, respectively). (D) Immunofluorescence of $\alpha$-SMA and calponin of day 6 TGF- $\beta 1-$ induced MAPC-SMCs from human MAPCs and porcine MAPCs.

suspension of $3 \times 10^{6}$ cells $/ \mathrm{ml}$ were combined at a ratio of 4:1:1. Samples were immediately plated or injected into vascular molds and placed at $37^{\circ} \mathrm{C}$ for 30 minutes. Following polymerization, construct medium (high-glucose DMEM, Penstrep, $10 \%$ FBS, $2.5 \mathrm{ng} / \mathrm{ml}$ TGF- $\beta 1,5 \mathrm{ng} / \mathrm{ml}$ PDGF-BB, $2 \mu \mathrm{g} / \mathrm{ml}$ insulin [Sigma-Aldrich], and $1 \mathrm{mg} / \mathrm{ml}$ aminohexanoic acid [Sigma-Aldrich]) was added to the samples, with changes every 2 days for the duration of the experiment. Samples were tested for mechanical properties using an MTS MicroBionix instrument. Each sample was preconditioned uniaxially for 6 cycles at a quasi-static rate of $2 \mathrm{~mm} / \mathrm{min}$ and a maximum displacement of $2 \mathrm{~mm}$. Samples were then uniaxially stretched to failure at a rate of $2 \mathrm{~mm} /$ min. Collagen and elastin content was quantified by hydroxyproline assay and alkaline extraction, respectively, as previously described (4).

Mechanical conditioning. CD was performed in a bioreactor created in our laboratory and described previously (39). Briefly, samples were created in a tubular mold around a Teflon mandrel and cultured for 2 weeks under normal culture conditions. Samples were then transferred to distensible mandrels made of latex tubing (Kent Elastomer Products) and exposed to either $5 \%$ strain, $0.5 \mathrm{~Hz}$, and $12.5 \%$ duty cycle or static conditions for 3 weeks, with medium changes every 2 days.

Electrophysiology. The patch-clamp amplifiers were Axopatch 200B (Axon Instruments) in all voltage-clamp experiments. Offset potentials were nulled directly before formation of a seal. Capacitance and series resistance were corrected (usually $80 \%$ ). To examine L-type $\mathrm{Ca}^{2+}$ currents, the extracellular solution contained (in $\mathrm{mM}$ ) $140 \mathrm{NaCl}, 2.7 \mathrm{KCl}, 10 \mathrm{BaCl}_{2}, 10$ HEPES ( $\mathrm{pH}$ 7.4). The pipette solution contained (in mM) $100 \mathrm{CsCl}, 30 \mathrm{CsF}$, $2 \mathrm{MgCl}_{2}, 4$ ATP-Mg, 10 EGTA, 10 HEPES (pH 7.2 adjusted with CsOH). Cells were voltage clamped at a holding potential of $-90 \mathrm{mV}$, and currents were evoked by $+10-\mathrm{mV}$ steps to $+50 \mathrm{mV}$ using test pulses of 120 - $\mathrm{ms}$ duration at a rate of $0.1 \mathrm{~Hz}$. Data were recorded and analyzed with pClamp 8.2 software (Axon Instruments).
Contractility studies. F-MAPC-SMC rings were suspended in stirrups in organ chambers (Radnoti Glass Technology Inc.) for measurement of isometric force, as previously described (50). Briefly, chambers containing samples were filled with Earle's balanced salt solution (in $\mathrm{mM}$ : $1.8 \mathrm{CaCl}_{2}, 0.8 \mathrm{MgSO}_{4}, 5.4 \mathrm{KCl}, 116.2 \mathrm{NaCl}, 1.0 \mathrm{NaH}_{2} \mathrm{PO}_{4}, 5.6$ glucose, and $26.2 \mathrm{NaHCO}_{3}$; all from Sigma-Aldrich) and bubbled with $21 \% \mathrm{O}_{2}$, $5 \% \mathrm{CO}_{2}, 74 \% \mathrm{~N}_{2}$ (normoxic, or similar to air; $\mathrm{pO}_{2} ; 120-150 \mathrm{mmHg}$ ) gases. Experimentally, temperature was kept at $37^{\circ} \mathrm{C} ; \mathrm{pCO}_{2}$ was $26-30$ $\mathrm{mmHg}$; and $\mathrm{pH}$ was 7.35-7.45. The rings were equilibrated at a resting tension of $400 \mathrm{mg}$ for at least 60 minutes and then exposed to $60 \mathrm{mM}$ $\mathrm{KCl}$ ( 8 minutes) 3 times at 30-minute intervals. The optimum tension was determined by measuring the maximum contractile response to 60 $\mathrm{mM} \mathrm{KCl}$ at varying basal tensions $(200-1,500 \mathrm{mg}$ tested in preliminary experiments). Data were recorded using a computer-based data-acquisition system (MacLab; ADInstruments Inc.). After a further 30-minute interval, the effects of $10 \mu \mathrm{M}$ serotonin, $300 \mathrm{nM}$ FPL64176, $100 \mathrm{nM}$ ET-1, $10 \mu \mathrm{M}$ acetylcholine, and $10 \mu \mathrm{M}$ Y-27632 (all from Sigma-Aldrich) were tested. The constructed MAPC-SMC rings were finally treated with water for 1 hour, and $\mathrm{KCl}$ response was measured again for the negative $\mathrm{KCl}$ control.

Statistics. Comparisons between 2 groups were analyzed using unpaired 2 -tailed Student's $t$ test $(P<0.05$ was considered significant). Data are shown as mean \pm SEM.

\section{Acknowledgments}

The authors would like to thank Sandy Johnson for her assistance in collagen and elastin quantification. We thank Aernout Luttun and Beatriz Pelacho for their rat endothelial and cardiac sequences. Funding was supplied by NIH grant RO1 DK-58295 (to C.M. Verfaillie), VA merit review and NIH grant RO1 HL65322 
(to E.K. Weir.), NIH grant RO1 HL60495 (to R.T. Tranquillo), and a research grant from Athersys Inc. to C.M. Verfaillie and J.J. Ross.

Received for publication February 10, 2006, and accepted in revised form September 19, 2006.

1. Owens, G.K. 1995. Regulation of differentiation of vascular smooth muscle cells. Physiol. Rev. 75:487-517.

2. Mahoney, W.M., and Schwartz, S.M. 2005. Defining smooth muscle cells and smooth muscle injury. J. Clin. Invest. 115:221-224. doi:10.1172/ JCI200524272.

3. Stegemann, J.P., Hong, H., and Nerem, R.M. 2005. Mechanical, biochemical, and extracellular matrix effects on vascular smooth muscle cell phenotype. J. Appl. Physiol. 98:2321-2327.

4. Ross, J.J., and Tranquillo, R.T. 2003. ECM gene expression correlates with in vitro tissue growth and development in fibrin gel remodeled by neonatal smooth muscle cells. Matrix Biol. 22:477-490.

5. Gittenberger-de Groot, A.C., DeRuiter, M.C., Bergwerff, M., and Poelmann, R.E. 1999. Smooth muscle cell origin and its relation to heterogeneity in development and disease. Arterioscler. Thromb. Vasc. Biol. 19:1589-1594.

6. Sobue, K., Hayashi, K., and Nishida, W. 1999. Expressional regulation of smooth muscle cell-specific genes in association with phenotypic modulation. Mol. Cell. Biochem. 190:105-118.

7. Owens, G.K., Kumar, M.S., and Wamhoff, B.R. 2004. Molecular regulation of vascular smooth muscle cell differentiation in development and disease. Physiol. Rev. 84:767-801.

8. Van der Loop, F., Schaart, G., Timmer, E., Ramaekers, F., and van Eys, G. 1996. Smoothelin, a novel cytoskeletal protein specific for smooth muscle cells. J. Cell Biol. 134:401-411.

9. Christen, T., et al. 2001. Mechanisms of neointima formation and remodeling in the porcine coronary artery. Circulation. 103:882-888.

10. Jain, M.K., et al. 1996. Molecular cloning and characterization of SmLIM, a developmentally regulated LIM protein preferentially expressed in aortic smooth muscle cells. J. Biol. Chem. 271:10194-10199.

11. Kumar, M.S., and Owens, G.K. 2003. Combinatorial control of smooth muscle-specific gene expression. Arterioscler. Thromb. Vasc. Biol. 23:737-747.

12. Dickson, M.C., et al. 1995. Defective haematopoiesis and vasculogenesis in transforming growth factorbeta 1 knock out mice. Development. 121:1845-1854.

13. Lindahl, P., Johansson, B.R., Leveen, P., and Betsholtz, C. 1997. Pericyte loss and microaneurysm formation in PDGF-B-deficient mice. Science. 277:242-245.

14. Riha, G.M., Lin, P.H., Lumsden, A.B., Yao, Q., and Chen, C. 2005. Roles of hemodynamic forces in vascular cell differentiation. Ann. Biomed. Eng. 33:772-779.

15. Drab, M., et al. 1997. From totipotent embryonic stem cells to spontaneously contracting smooth muscle cells: a retinoic acid and db-cAMP in vitro differentiation model. FASEB J. 11:905-915.

16. Sinha, S., Hoofnagle, M.H., Kingston, P.A., McCanna, M.E., and Owens, G.K. 2004. Transforming growth factor-beta1 signaling contributes to development of smooth muscle cells from embryonic stem cells. Am. J. Physiol. Cell Physiol. 287:C1560-C1568.

17. Galmiche, M., Koteliansky, V., Briere, J., Herve, P., and Charbord, P. 1993. Stromal cells from human long-term marrow cultures are mesenchymal cells
Address correspondence to: Catherine M. Verfaillie, Stamcel Instituut, Leuven, Katholieke Universiteit Leuven, Campus Gasthuisberg, Herestraat 49, 3000 Leuven, Belgium. Phone: 3216-33-02-95; Fax: 32-16-33-02-94; E-mail: catherine.verfaillie@ med.kuleuven.be. that differentiate following a vascular smooth muscle differentiation pathway. Blood. 82:66-76.

18. Yoon, Y.S., et al. 2005. Clonally expanded novel multipotent stem cells from human bone marrow regenerate myocardium after myocardial infarction. J. Clin. Invest. 115:326-338. doi:10.1172/ JCI200522326.

19. Tsai, R.Y., and McKay, R.D. 2000. Cell contact regulates fate choice by cortical stem cells. J. Neurosci. 20:3725-3735.

20. Tagliafico, E., et al. 2004. TGF $\beta /$ BMP activate the smooth muscle/bone differentiation programs in mesoangioblasts. J. Cell. Sci. 117:4377-4388.

21. Reyes, M., et al. 2001. Purification and ex vivo expansion of postnatal human marrow mesodermal progenitor cells. Blood. 98:2615-2625.

22. Jiang, Y., et al. 2002. Pluripotent nature of adult marrow derived mesenchymal stem cells. Nature. 418:41-49.

23. Jiang, Y., Henderson, D., Blackstad, M., Chen, A., Miller, R.F., and Verfaillie, C.M. 2003. Neuroectodermal differentiation from mouse multipotent adult progenitor cells. Proc. Natl. Acad. Sci. U. S. A. 100(Suppl 1):11854-11860.

24. Scholer, H.R., Hatzopoulos, A.K., Balling, R., Suzuki, N., and Gruss, P. 1989. A family of octamer-specific proteins present during mouse embryogenesis: evidence for germline-specific expression of an Oct factor. $E M B O J .8: 2543-2550$.

25. Breyer, A., Estharabadi, N., Lien, L., and Jiang, Y. 2006. Multipotent adult progenitor cell (MAPC) isolation and culture procedures. Exp. Hematol. In press.

26. Pittenger, M.F., et al. 1999. Multilineage potential of adult human mesenchymal stem cells. Science. 284:143-147.

27. Minasi, M.G., et al. 2002. The meso-angioblast: a multipotent, self-renewing cell that originates from the dorsal aorta and differentiates into most mesodermal tissues. Development. 129:2773-2783.

28. Kogler, G., et al. 2004. A new human somatic stem cell from placental cord blood with intrinsic pluripotent differentiation potential. J. Exp. Med. 200:123-135.

29. D'Ippolito, G., et al. 2004. Marrow-isolated adult multilineage inducible (MIAMI) cells, a unique population of postnatal young and old human cells with extensive expansion and differentiation potential. J. Cell. Sci. 117:2971-2981.

30. Holycross, B.J., Blank, R.S., Thompson, M.M., Peach, M.J., and Owens, G.K. 1992. Platelet-derived growth factor-BB-induced suppression of smooth muscle cell differentiation. Circ. Res. 71:1525-1532.

31. Blank, R.S., and Owens, G.K. 1990. Platelet-derived growth factor regulates actin isoform expression and growth state in cultured rat aortic smooth muscle cells. J. Cell. Physiol. 142:635-642.

32. Zhang, J.C., et al. 2001. Analysis of SM22alphadeficient mice reveals unanticipated insights into smooth muscle cell differentiation and function. Mol. Cell. Biol. 21:1336-1344.

33. Herring, B.P., Lyons, G.E., Hoggatt, A.M., and Gallagher, P.J. 2001. Telokin expression is restricted to smooth muscle tissues during mouse development. Am. J. Physiol. Cell Physiol. 280:C12-C21.

34. Qian, J., Kumar, A., Szucsik, J.C., and Lessard, J.L.
1996. Tissue and developmental specific expression of murine smooth muscle gamma-actin fusion genes in transgenic mice. Dev. Dyn. 207:135-144.

35. Moosmang, S., Lenhardt, P., Haider, N., Hofmann, F., and Wegener, J.W. 2005. Mouse models to study L-type calcium channel function. Pharmacol. Ther. 106:347-355

36. Grassl, E.D., Oegema, T.R., and Tranquillo, R.T. 2003. A fibrin-based arterial media equivalent. J. Biomed. Mater. Res. A. 66:550-561.

37. Neidert, M.R., Lee, E.S., Oegema, T.R., and Tranquillo, R.T. 2002. Enhanced fibrin remodeling in vitro with TGF-beta1, insulin and plasmin for improved tissue-equivalents. Biomaterials. 23:3717-3731.

38. Reusch, P., Wagdy, H., Reusch, R., Wilson, E., and Ives, H.E. 1996. Mechanical strain increases smooth muscle and decreases nonmuscle myosin expression in rat vascular smooth muscle cells. Circ. Res. 79:1046-1053.

39. Isenberg, B.C., and Tranquillo, R.T. 2003. Longterm cyclic distention enhances the mechanical properties of collagen-based media-equivalents. Ann. Biomed. Eng. 31:937-949.

40. Li, L., Miano, J.M., Cserjesi, P., and Olson, E.N. 1996. SM22 alpha, a marker of adult smooth muscle, is expressed in multiple myogenic lineages during embryogenesis. Circ. Res. 78:188-195.

41. Yoshida, T., and Owens, G.K. 2005. Molecular determinants of vascular smooth muscle cell diversity. Circ. Res. 96:280-291.

42. Chang, D.F., et al. 2003. Cysteine-rich LIM-only proteins CRP1 and CRP2 are potent smooth muscle differentiation cofactors. Dev. Cell. 4:107-118.

43. Hellstrom, M., Kalen, M., Lindahl, P., Abramsson, A., and Betsholtz, C. 1999. Role of PDGF-B and PDGFR-beta in recruitment of vascular smooth muscle cells and pericytes during embryonic blood vessel formation in the mouse. Development. 126:3047-3055

44. Dandre, F., and Owens, G.K. 2004. Platelet-derived growth factor-BB and Ets-1 transcription factor negatively regulate transcription of multiple smooth muscle cell differentiation marker genes. Am. J. Physiol. Heart Circ. Physiol. 286:H2042-H2051.

45. Rodriguez, L.V., et al. 2006. Clonogenic multipotent stem cells in human adipose tissue differentiate into functional smooth muscle cells. Proc. Natl. Acad. Sci. U. S. A. 103:12167-12172.

46. Sinha, S., et al. 2006. Assessment of contractility of purified smooth muscle cells derived from embryonic stem cells. Stem Cells. 24:1678-1688.

47. Zeng, L., et al. 2006. Multi-potent adult progenitor cells from swine bone marrow. Stem Cells. 24:2355-2366.

48. Reyes, M., et al. 2002. Origin of endothelial progenitors in human postnatal bone marrow. J. Clin. Invest. 109:337-346. doi:10.1172/JCI200214327.

49. Schwartz, R.E., et al. 2002. Multipotent adult progenitor cells from bone marrow differentiate into functional hepatocyte-like cells. J. Clin. Invest. 109:1291-1302. doi:10.1172/JCI200215182.

50. Hong, Z., et al. 2005. Pergolide is an inhibitor of voltage-gated potassium channels, including $\mathrm{Kv} 1.5$, and causes pulmonary vasoconstriction. Circulation. 112:1494-1499. 